\title{
Seismic stability of the 20-storey reinforced concrete frame building by various normative documents
}

\author{
Levon Avetisyan* \\ Moscow State University of Civil Engineering, Yaroslavskoe shosse, 26, Moscow, 129337, Russia
}

\begin{abstract}
This article provides a comparative analysis of three different regulatory documents on earthquake-resistant construction. For the calculation example and comparative analysis, the calculation of a 20storey reinforced concrete frame building for seismic resistance according to Russian, European and American normative documents is made. A comparative analysis of the calculation results of strength and deformation characteristics is made, seismic resistance is evaluated according to the considered norms. The Pushover analysis at different spatial rigidity of the building under study was carried out, the values of the damage coefficient were obtained and compared. It is established that European and American regulations impose more stringent requirements for seismic resistance of the building than the Russian regulatory document, but due to the high safety factors and calculation algorithms at the same loads, the building calculated according to Russian standards has less seismic resistance in the calculation example. This follows from the results of the calculation of the building considered. The displacements along the $\mathrm{x}$ and $\mathrm{Y}$ axes in the case of Russian norms are more than 2 times higher. At the same time, the greatest deflections were obtained in the calculation of the European regulations, with $35 \%$ more than the maximum. Pushover analysis in the calculation of the Russian regulations showed a very small coefficient of permissible damage $\mathrm{K} 1,36 \%$ less than the minimum. After increasing the spatial stiffness of its value increased by more than 2 times and began to fully satisfy the seismic resistance. In all calculated cases, there was an increase in the coefficient $\mathrm{K} 1$ with an increase in the rigidity of the building, and the values themselves sought to close each other's numbers.
\end{abstract}

\section{Introduction}

Emergencies and natural disasters, in particular earthquakes, lead to the emergence of specific combinations of loads, leading to irreversible consequences. In this regard, the provision of seismic resistance is one of the most important tasks of calculation and operation of buildings and structures. The safety of people and minimize damage to buildings and structures under different load combinations is provided in accordance with a specific regulatory document in the design phase. Each country regulates its own regulatory document on the assessment of seismic resistance of buildings and structures. Currently, the

Corresponding author: AvetisyanLA@mgsu.ru 
main criteria for evaluation of seismic resistance are as follows: ensuring sufficient strength of structural elements, horizontal and vertical movement of the building must not exceed the permissible values, the study of oscillations of the building to eliminate the resonance effect, etc. by a Conventional method of nonlinear analysis of structures is Pushover analysis is a static nonlinear analysis that allows to assess the damage to the building. Since all existing norms for seismic resistance assessment are based on Russian, European or American normative documents, or developed on the same principle, at present these normative documents are of the greatest scientific interest for us. The General criterion for correctly assessing the seismic stability of buildings in the calculation of different regulations is the coefficient of permissible damage $\mathrm{K} 1$, which allows you to assess the reaction of the building outside the elasticity during seismic action.

\section{Main part}

The work of structures outside the elasticity (i.e. with the implementation of the plastic phase of deformation), taken into account by the coefficient of permissible damage K1, has its analogue in En 1998-1 " q " - the coefficient of behavior. The value of the" coefficient of acceptable damage/behavior " varies from zero to one. In fact, it is a characteristic of the limiting state of the structure, and the determination of the scientifically based value of this parameter is the most important task in assessing the seismic stability of the building frame, the successful solution of which ensures the reliability of the assessment of seismic resistance of buildings and structures.

The design standards developed recently, allowed the possibility of the material structures outside the elasticity. The nonlinear behavior of structures is assumed, and even the destruction of individual bearing elements is allowed, which should be relatively easily accessible for inspection and repair, and the failure of which does not lead to global destruction.

The calculation of structures taking into account the nonlinear behavior of individual elements of the structure requires the use of more complex mathematical models and theories.

Currently, the Russian norms for earthquake-resistant construction still use the linearspectral method. This method allows us to accurately assess the reaction of the system operating in the elastic stage under seismic action. But as the system moves into an inelastic stage of operation, the accuracy of the estimate decreases. Weak validity of the coefficient $\mathrm{K} 1$ can greatly understate the reaction of the system, allowing plastic deformation.

In this regard, there is a need to use methods that take into account the non-linear operation of materials and structures as a whole. One such method is the nonlinear dynamic analysis "Nonlinear Pushover analysis", which shows the work of the structure beyond elasticity.

In the Pushover analysis [1], the transverse force vector F-showing the direction and magnitude of the impact, is determined by the formula:

$$
F=p \cdot W \cdot \Phi
$$

where $\mathrm{p}$ - is the parameter that controls the transverse force;

$\mathrm{W}$ - mass matrix;

$\mathrm{F}$ - a matrix of forms of natural oscillations.

The essential assumption is that the system of differential equations is considered, in which only horizontal degrees of freedom are taken into account:

$$
W \ddot{U}+R=-W I a_{g},
$$

where $\mathrm{U}$ and $\mathrm{R}$ - are vectors of displacements and internal forces;

I- unit vector;

$a_{g}$ - is the acceleration of the Foundation soil. 
The main and the most important assumption in the framework of nonlinear static analysis is the constancy of the form of oscillations $f$, that is, it does not change during the oscillation of the structure during the movement of the base. Note also that there are no dissipative forces in the expression (1.2). They are already included in the calculated acceleration spectrum.

In American standards, a modified method of the carrier spectrum is used. The most well-known method of nonlinear static analysis is the method of the carrier spectrum (Capacity Spectrum Method, CSM). This method was first proposed by Freeman and then approved in ATC-40.

For the comparative analysis of seismic resistance assessment according to Russian, European and American normative documents, the calculation of reinforced concrete 20storey frame building was carried out with the help of PC LIRA-CAD $18 \mathrm{~K} 1$.

The calculation scheme is identical for all settlement cases. The geometric model is shown in Fig. 1.

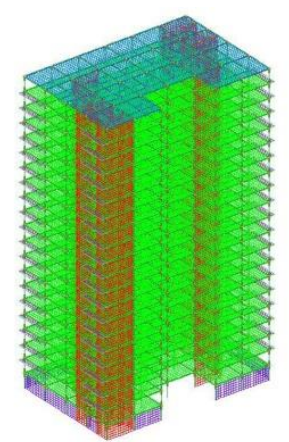

Fig. 1. A design scheme of the building in LIRA-SAPR

To ensure spatial rigidity, stairwells, Elevator shafts, balconies, stiffness diaphragms are provided, as well as an underground technical floor with a height of $2.6 \mathrm{~m}$.

Sections of elements: columns-400x400 mm, beams-400x600 mm, floor slabs with a thickness of $200 \mathrm{~mm}$. the thickness of the stiffness diaphragms, which are the walls of Elevator shafts and stairwells $200 \mathrm{~mm}$.

According to the results of calculation of seismic resistance according to various normative documents by spectral method, the following values of displacements are obtained (see table. 1).

Table 1. Displacements and deflections of the structure

\begin{tabular}{|c|c|c|c|c|}
\hline \multicolumn{2}{|c|}{ Deformations } & $\begin{array}{c}\text { SP } \\
14.13330 .2014\end{array}$ & En 1998-1 & \multirow{2}{*}{ IBC 2015 } \\
\hline \multicolumn{2}{|c|}{ Maximum deflection } & 26,2 & 31 & 23 \\
\hline \multirow{2}{*}{ Movement } & $\mathrm{X}$ & 69,3 & 29 & 9,22 \\
\cline { 2 - 5 } & $\mathrm{Y}$ & 45,2 & 36,7 & 14,7 \\
\hline
\end{tabular}

As can be seen from the above table, the building experiences the greatest horizontal movements when calculated according to Russian normative documents. This is due to the calculation algorithms and combination coefficients. Despite this, the seismic resistance of the building is provided by all regulatory documents.

The building, calculated by the spectral method according to the Russian normative documents, has the largest displacement along the $\mathrm{x}, \mathrm{Y}$ axes relative to the base of the building. The $\mathrm{x}-$ axis is $58 \%$ more relative to European norms and $86 \%$ more relative to 
American norms; the $\mathrm{Y}$-axis is $18 \%$ more relative to European norms and $67 \%$ more relative to American norms.

To assess the damage to the building and the work of structures beyond the elastic limits, it is necessary to carry out a Pushover analysis.

The analysis was carried out by Pushover according to Russian, European and American normative documents.

When calculating by [2], a state point is obtained from the results of Pushover analysis, figure 2. For a given point was calculated VAT of the entire system and determined the coefficient of compliance $\mu=5,0792$. Thus the coefficient K1

$$
\mathrm{K} 1=\frac{1}{\mu} \approx 0.2,
$$

The value of $\mathrm{K} 1$ is less than the value specified in the calculation (0.3), which indicates the lack of seismic resistance of the building and the large damage in the conditions of intensity of seismic impact at 8 points.

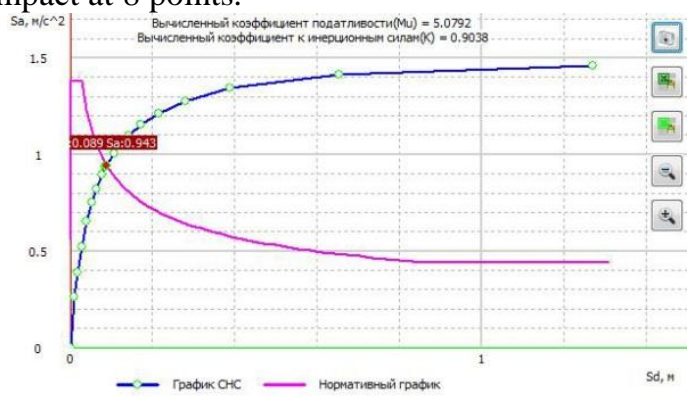

Fig. 2. The bearing capacity curve of the building by [2]

Thus, when calculated according to the Russian regulations, it is necessary to increase the rigidity of the designed building to ensure seismic resistance.

According to the results of Pushover analysis, a state point is obtained when calculating by [3], figure 3 . For this point, the VAT of the whole system was calculated and the compliance coefficient $\mu=3.22$ was determined . Coefficient of permissible damage K1:

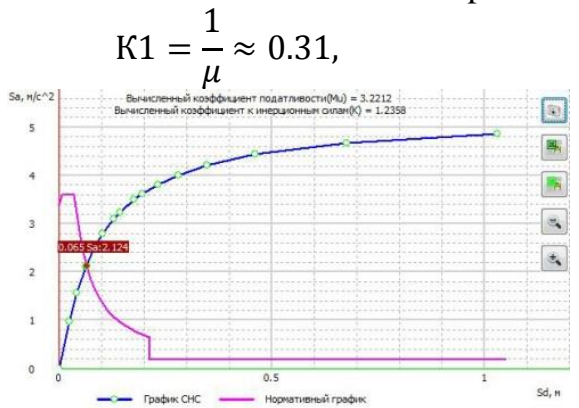

Fig. 3. The bearing capacity curve of the building by [3]

Therefore, seismic resistance of the building according to the European normative documents is provided,

When calculating by [4], the state point is obtained, figure 4 . The VAT of the whole system was calculated and the compliance coefficient $\mu=4.82$ was determined . In the case:

$$
\mathrm{\kappa} 1=\frac{1}{\mu} \approx 0.2,
$$




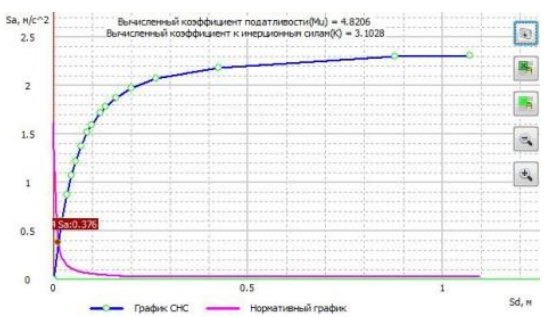

Fig. 4. The bearing capacity curve of the building by [4]

The calculation of the building according to the American regulations shows that seismic resistance is not provided, to increase it is necessary to increase the spatial rigidity of the building.

According to the results of the Pushover analysis, the building calculated according to Russian and American normative documents does not have sufficient seismic resistance, the coefficient $\mathrm{K} 1$ is less than the specified values - 0.3. This means that the buildings will experience significant damage during the seismic impact. The calculation according to the European regulations showed the value of the coefficient of permissible damage within the norm.

To ensure seismic resistance and estimate the magnitude of $\mathrm{K} 1$ is made of the building to the seismic excitation, with the increase of spatial rigidity (Fig. 5).

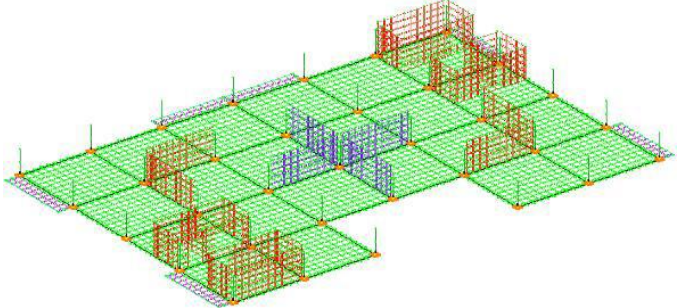

Fig. 5. Typical building floor plan after adding rigidity diaphragms

According to the results of the calculation, we obtain the following values of the coefficient K1, (table 2). As can be seen from the results, the seismic resistance of the building with increased stiffness in all regulatory documents is provided.

Table 2. Values of coefficient K1

\begin{tabular}{|c|c|c|}
\hline \multirow{2}{*}{} & \multicolumn{2}{|c|}{ The Coefficient K1 } \\
\cline { 2 - 3 } & 1st variant & 2nd variant \\
\hline SP 14.13330.2014 & 0,19 & 0,43 \\
\hline En 1998-1 & 0,31 & 0,4 \\
\hline IBC 2015 & 0,2 & 0,37 \\
\hline
\end{tabular}

After increasing the spatial stiffness of K1 [5-7] also increased, the results show close to each other values. To check the revealed trend of approximation of the values of $\mathrm{K} 1$, we additionally increase the spatial stiffness and recalculate this parameter.

Figure 6 shows the new floor plan after increasing the spatial stiffness. 


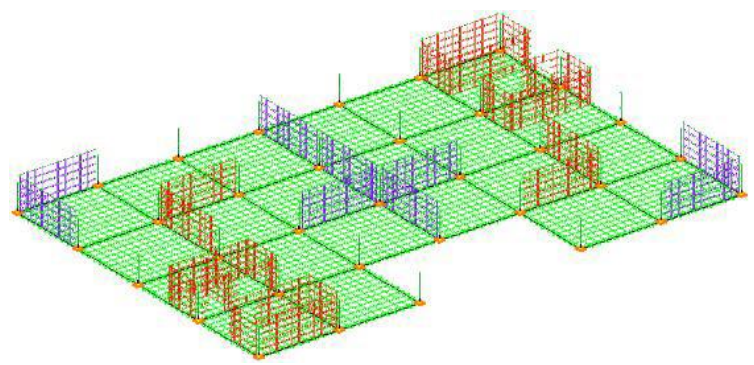

Fig. 6. Typical floor Plan after increasing spatial stiffness

After increasing the rigidity and recalculation of the building for all regulatory documents obtained the following values K1, Table 3 .

Table 3. Values of coefficient K1

\begin{tabular}{|c|c|c|c|}
\hline \multirow{2}{*}{} & \multicolumn{3}{|c|}{ The Coefficient K1 } \\
\cline { 2 - 4 } & 1st variant & 2nd variant & 3rd variant \\
\hline SP 14.13330.2014 & 0,19 & 0,43 & 0,44 \\
\hline En 1998-1 & 0,31 & 0,4 & 0,42 \\
\hline IBC 2015 & 0,2 & 0,37 & 0,41 \\
\hline
\end{tabular}

As can be seen from table 3, with a subsequent increase in the rigidity of the building, the coefficient $\mathrm{K} 1$ for all normative documents tends to the same value, or close to each other values.

\section{Conclusion}

1. The building is calculated by the spectral method in Russian 1 . The building, calculated by the spectral method according to the Russian normative documents, has the greatest displacement along the $\mathrm{x}, \mathrm{Y}$ axes relative to the base of the building. The $\mathrm{x}$-axis is $58 \%$ more than European standards and $86 \%$ more than American standards; the Y-axis is $18 \%$ more than European standards and $67 \%$ more than American standards.

2. The building, calculated according to European standards, does not pass the criterion of movement along the $\mathrm{Z}-31 \mathrm{~mm}$ axis, which is $35 \%$ more than the permissible value $(\mathrm{f}=$ $20 \mathrm{~mm}$ ).

3. The rag analysis in the calculation of Russian standards showed that the building has a deficit of seismic resistance due to the small value of the damage coefficient $\mathrm{K} 1-0.19$, which is $36 \%$ less than the permissible value (0.3).

4. Rag analysis in the calculation according to EN 1998-1 showed the value of the coefficient $\mathrm{K} 1$ in the normal range $(0.31)$, which indicates a sufficient earthquake resistance of the building.

5. Rag analysis in the calculation of regulations showed us unacceptably small value of the coefficient $\mathrm{K} 1-0.2$, which is $35 \%$ less than the allowable value $(0.3)$, the building has a lack of seismic resistance.

6. As the stiffness of the building increases, the coefficient $\mathrm{K} 1$ increases. The results show to 1 that the values calculated by different rules are close to each other.

7. Rag analysis allows us to consider the nonlinear characteristics of materials with the highest accuracy to assess the seismic stability of buildings, which allows it to be accepted as the main criterion for different positions. 


\section{References}

1. O. V. Mkrtychev, G. A. XXI Russian-Slovak-Polish Seminar, Theoretical Foundation of Civil Engineering, Moscow - Archangelsk. - pp. 177186

2. SP 14.13330.2014 (updated SNiP II-7-81*). Construction in seismic areas. (2014)

3. EN 1998-1 Eurocode 8. Design of earthquake-resistant structures. (1998)

4. International Building Code, 690 p. (2015)

5. L. A. Avetisyan, T. S. Skornyakov. Construction and reconstruction. No. 1 (75).-P. 80$87 ;(2018)$

6. A. I. Bedov, A. G. Tamrazyan, R. G. Harutyunyan. Earthquake engineering. Safety of structures. No. 4. P. 36-42. (1998)

7. A. G. Tamrazyan, R. A. Atabekyan. Housing construction. No. 6. P. 19. (2003) 